\title{
Erratum to: Information and Communication Technologies in Education
}

\author{
Harriet Taylor ${ }^{1}$ and Pieter Hogenbirk ${ }^{2}$ \\ 1 Louisiana State University, USA \\ ${ }^{2}$ CPS, The Netherlands
}

\section{Erratum to: \\ H. Taylor and P. Hogenbirk (Eds.) \\ Information and Communication Technologies in Education \\ DOI: $10.1007 / 978-0-387-35403-3$}

The book was inadvertently published with an incorrect name of the copyright holder. The name of the copyright holder for this book is: (c) IFIP International Federation for Information Processing. The book has been updated with the changes.

The updated original online version for this book can be found at DOI: 10.1007/978-0-387-35403-3 